\title{
Mg-Cr Layered Double Hydroxide (LDH) Intercalated with Sodium Dodecyl Sulfate as Sorbent for Alizarine Red-S in Aqueous Solutions
}

\author{
I.M. Ahmed ${ }^{\text {a, b }}$ \\ ${ }^{a}$ Chemistry Department, College of Science, Jouf University, Sakaka, Saudi Arabia \\ ${ }^{b}$ Hot Laboratories and Waste Management Center, Egyptian Atomic Energy Authority, Cairo, Egypt
}

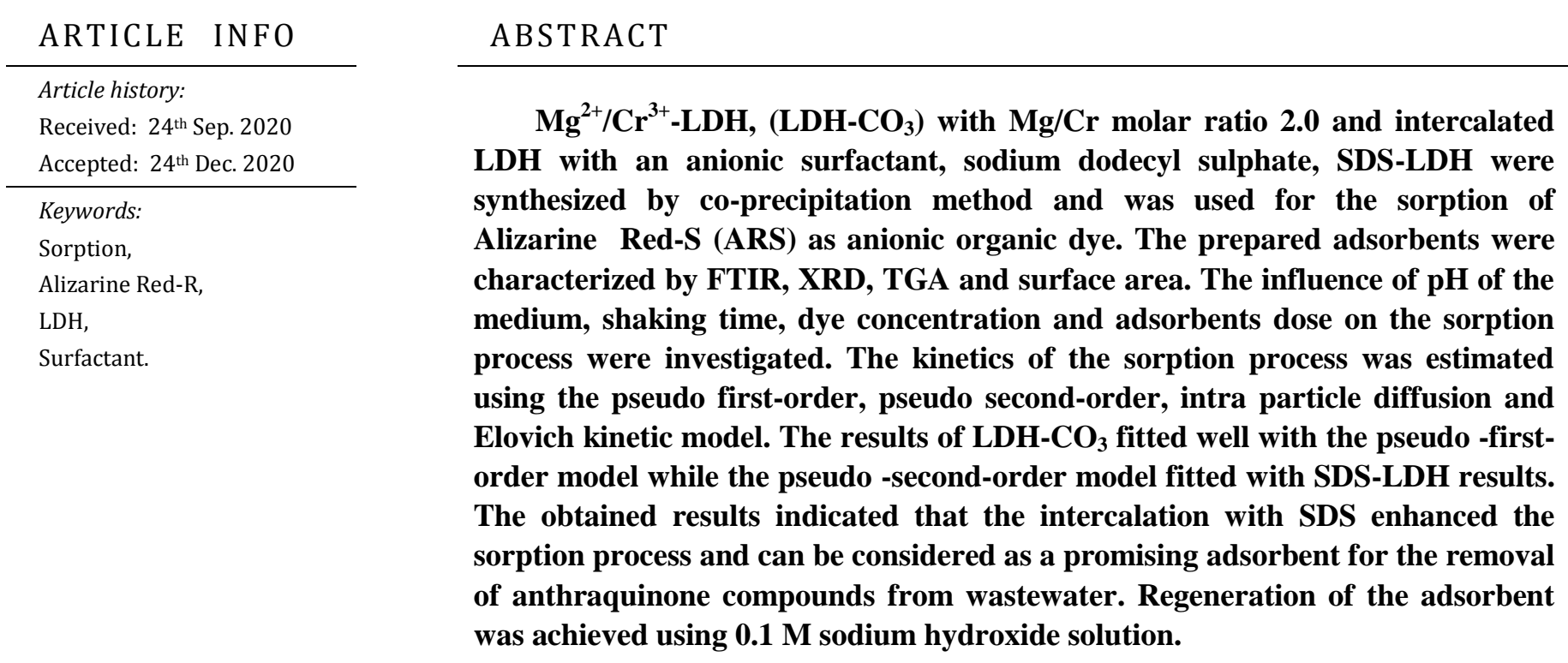

\section{INTRODUCTION}

Pollution control is one of the important environmental issues in the world. Large quantities of dyes that are produced from many industries as leather tanning, paints, paper, pharmaceuticals and food are discharged in the water streams. Fifteen percent of the total dyes produced annually are released in the water streams during textiles industries. As the dyes are nonbiodegradable and cause the coloration of water which prevents the penetration of light in the water systems causing hazardous effects to all aquatic living organisms as most of them are carcinogenic and mutagenic [1-3]. Many techniques were applied for the removal of dyes as ozonation [4], electrocoagulation [5, 6], photodegradation [7], aerobic and anaerobic biodegradation [8-10], biosorption [11], ion exchange [12], solvent extraction [13], oxidation [14] and precipitation [15] however, these techniques have some drawbacks as dyes are tailored to be resistant to degradation and even the degradable species may be more toxic and not economically feasible. Adsorption is an effective method for dye removal due to the ease, efficient and low cost operation. Many adsorbents were investigated for the removal of cationic and anionic dyes using low cost adsorbents as natural clays that are generally hydrous aluminosilicate with high surface areas and high cation exchange [1]. The most used clays as adsorbents are montmorillonite and kaolinite group clays with the general formula of $\mathrm{Al}_{2} \mathrm{Si}_{2} \mathrm{O}_{5}(\mathrm{OH})_{4}$ [16], industrial wastes as metal hydroxide sludge [17, 18 ], red mud [1921], zerovalent iron [22], activated carbon [23], organoclay [24] and biosorbent materials [25-27]. The layered double hydroxides (LDHs) have a general formula $\left[\mathrm{M}_{1-\mathrm{x}}{ }^{2+} \mathrm{M}_{\mathrm{x}}{ }^{3+}(\mathrm{OH})_{2} \mathrm{~A}_{\mathrm{x} / \mathrm{n}}{ }^{-} \cdot \mathrm{mH}_{2} \mathrm{O}\right]$, where $\mathrm{M}$ ${ }^{2+}$ is a divalent cation, $\mathrm{M}^{3+}$ is a trivalent metal cation and $\mathrm{A}^{\mathrm{n}-}$ is the interlayer anion that are found on the surface and/or in the interlayer spaces. Several methods were proposed for the preparation of $\mathrm{LDH}$ as co-precipitation, hydrothermal methods and mechanochemical synthesis 
etc. Many factors affect the synthesis of LDHs by coprecipitation as the $\mathrm{pH}$, precipitation method, precipitation temperature, reagent concentration, aging and the presence of impurities [28]. The surface and interlayer anions and water molecules can be exchanged with other inorganic and organic anions from contaminated waters [29]. LDHs were used as adsorbents for the removal of heavy metals, radionuclides, oxyanions [30-33], dyes [34-40]. Intrercalation using organic surfactants to increase the hydrophobicity have found many applications in the removal of organic materials from industrial wastewater.

Anthraquinone compounds have many applications in dyes, metallochrome indicators, drugs, or staining the biological samples. From these dyes, Alizarin Red S (9,10-dihydro-3,4-dihydroxy-9,10-dioxo-2 anthracenesulfonic acid) (ARS) that is commonly used in staining calcium deposits in tissues, in geology to stain and differentiate carbonate minerals, ARS is used as spectrophotometric determination of some elements of nuclear interest as uranium [41], Zirconium [42], Aluminum [43], etc., and in dyeing textiles, such dye cannot be completely degraded by the above mentioned methods due to its complex structure and its thermal and optical stability. For these reasons, this category of dyes attract attention of researchers to find a simple and low cost technique for the removal of ARS.

In this paper, the possibility of using $\mathrm{LDH}-\mathrm{CO}_{3}$ and SDS-LDH for the sorption behavior of ARS from aqueous solution has been investigated in order to examine the effect of intercalation on the sorption process.

\section{EXPERIMENTAL}

\subsection{Materials and methods}

Alizarine- Red S was used as delivered by the supplier (Riedl-de Haen,). Magnesium chloride hexahydrate, chromium(III) chloride hexahydrate, sodium carbonate were purchased from Merck. For all experiments, double distilled water was used.

\subsection{Synthesis of the adsorbents}

\subsection{1 $\mathrm{LDH}-\mathrm{CO}_{3}$}

LDH- $\mathrm{CO}_{3}$ was synthesized by the co-precipitation method using $\mathrm{MgCl}_{2} \cdot 6 \mathrm{H}_{2} \mathrm{O}$ and $\mathrm{CrCl}_{3} \cdot 6 \mathrm{H}_{2} \mathrm{O}$. The $\mathrm{Mg}: \mathrm{Cr}$ molar ratio of $2: 1$ was obtained by using $0.1 \mathrm{~mol} / \mathrm{L}$ $\mathrm{Mg}^{2+}$ and $0.05 \mathrm{~mol} / \mathrm{L} \mathrm{Cr}^{3+} .100 .0 \mathrm{~mL}$ of $2.0 \mathrm{M} \mathrm{Na}_{2} \mathrm{CO}_{3}$ was added dropwise to $100.0 \mathrm{~mL}$ of the above mentioned mixture that stirred for $18 \mathrm{~h}$ and the $\mathrm{pH}$ was maintained in the range of $10 \pm 0.1$. The final greenish blue precipitate was aged for $24 \mathrm{~h}$ at $80{ }^{\circ} \mathrm{C}$, then filtered, washed with distilled water and dried at $60{ }^{\circ} \mathrm{C}$ overnight.

\subsubsection{SDS-LDH}

$0.5 \mathrm{~g}$ of sodium dodecylsulfate (SDS) in $100 \mathrm{~mL}$ of distilled water was stirred with $5.0 \mathrm{~g}$ of $\left(\mathrm{LDH}-\mathrm{CO}_{3}\right)$ for $1.0 \mathrm{~h}$ at $353{ }^{\circ} \mathrm{K}$ in air. The suspension was then centrifuged and the solid was washed three times with hot distilled water and dried at $338{ }^{\circ} \mathrm{K}$ overnight, Fig.1 represents schematic structure of both $\mathrm{LDH}-\mathrm{CO}_{3}$ and SDS-LDH.

\subsection{Instrumentation}

UV-Visible Recording Spectrophotometer (Cary 60, Agilent, USA) was used for estimation of ARS concentration. FT-IR spectra of $\mathrm{LDH}-\mathrm{CO}_{3}$ and SDSLDH before and after sorption were recorded at a wavelength range of $400-4000 \mathrm{~cm}^{-1}$ by Fourier Transform Infra-red Spectrometer (FTIR)IR-Tracer 100, Shimadzu, Japan. The pore structure and surface area were examined by nitrogen adsorption/desorption at $77^{\circ} \mathrm{K}$ using a gas sorption analyzer (Quantachrome, NOVA 4200 e series, USA). The thermal stability of the adsorbent was investigated by a Shimadzu, TGA 51thermal analyzer, at heating rate of $10{ }^{\circ} \mathrm{C} / \mathrm{min}$. XRD pattern of the adsorbent was measured using $\mathrm{CuKa}$ radiation by Shimadzo X-Ray powder diffractometer (XRD 7000) within $2 \theta$ ranging from 10 to $80^{\circ}$.

2.4 Sorption of ARS onto LDH-CO 3 and SDS-LDH $0.05 \mathrm{~g}$ of the adsorbents were equilibrated with 10 $\mathrm{mL}$ of $100 \mathrm{mg} / \mathrm{L}$ of ARS for $60.0 \mathrm{~min}$. at $\mathrm{pH} 6.0$, and the solution was centrifuged for ARS measurement by UV-Vis spectrophotometer at $555.0 \mathrm{~nm}$. The percent uptake (uptake \%) was calculated by the following equation:

$$
\text { uptake } \%=\frac{C_{o}-C_{e}}{C_{o}} \times 100
$$

The adsorption capacity of ARS, qe (mg/g), was calculated according to the equation:

$$
q_{e}=\left(C_{o}-C_{e}\right) \frac{V}{m}
$$

where $\mathrm{Co}, \mathrm{Ce}$ are the initial and equilibrium ARS concentration in $(\mathrm{mg} / \mathrm{L}), \mathrm{V}$ and $\mathrm{m}$ are the volume of the solution (L) and the mass of adsorbent (g), respectively. 


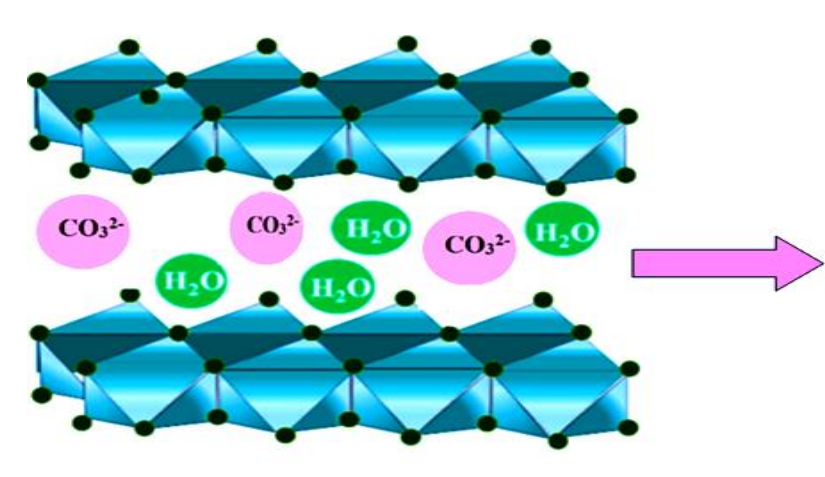

Fig. (1) Schematic structure of both $\mathrm{LDH}-\mathrm{CO}_{3}$ and SDS-LDH

\section{RESULTS AND DISCUSSION}

\subsection{Characterization of the adsorbent}

FT-IR spectra of $\mathrm{LDH}-\mathrm{CO}_{3}, \mathrm{SDS}(\mathrm{LDH})$, ARS and dye-loaded adsorbent are shown in Fig. 2. The spectrum of $\mathrm{LDH}-\mathrm{CO}_{3}$ shows the characteristic absorption bands of a hydroxyl group, at $3390 \mathrm{~cm}^{-1}$ due to the hydration of water molecules and $\mathrm{OH}$ groups of brucite like structure [29]. The band at 1446, 1367 and 873 vibration of interlayer $\mathrm{CO}_{3}{ }^{2-} \mathrm{cm}^{-1}$. In the SDS$\mathrm{LDH}$ bands at $2900,2800 \mathrm{~cm}^{-1} \mathrm{C}-\mathrm{H}$ stretch vibration bands are due to $\mathrm{CH}_{3}$ and $\mathrm{CH}_{2}$ group, $\mathrm{C}-\mathrm{H}$ bending vibration appears at $1400 \mathrm{~cm}^{-1}$. Loaded LDHs spectra show bands in the range of about 450 to $650 \mathrm{~cm}-1$ which are due to $\mathrm{O}-\mathrm{M}-\mathrm{O}, \mathrm{M}-\mathrm{O}-\mathrm{M}$ and $\mathrm{M}-\mathrm{O}-\mathrm{H}$ lattice vibrations [44], ARS shows peaks at 1665 and 1637 $\mathrm{cm}^{-1}$ that are referred to $\mathrm{C}=\mathrm{O}$ stretching vibration, the peaks at $1589 \mathrm{~cm}^{-1}$ are due to the $\mathrm{C}=\mathrm{C}$ bonds in benzene ring and the bands at $1439,1220,1068$ and $1150 \mathrm{~cm}^{-1}$ are referred to the sulfonic groups[45, 46].

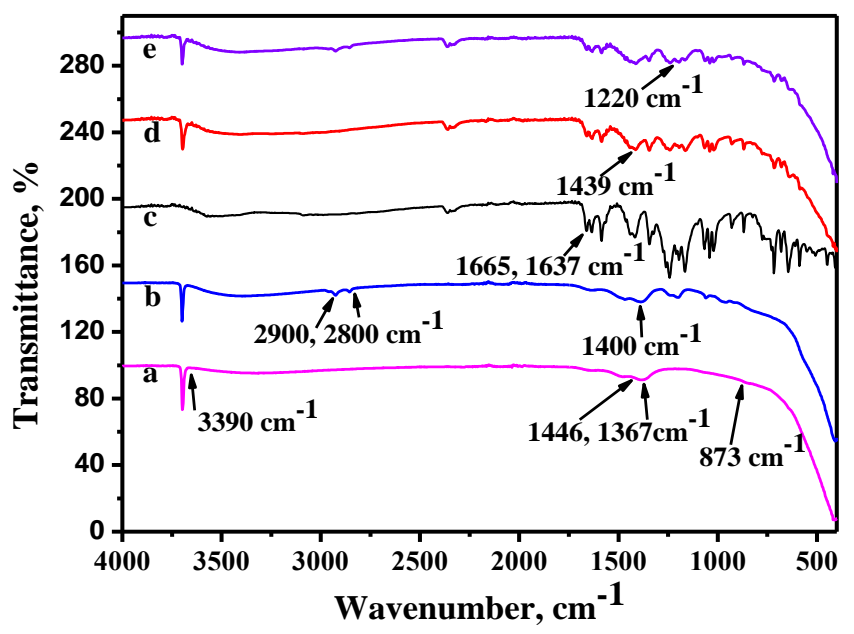

Fig. (2): FT-IR of Cl-LDH and SDS-LDH. [a- $\mathrm{LDH}^{-\mathrm{CO}_{3}}$; bSDS-LDH; c- ARS; d- LDH-CO ${ }_{3}$-ARS; e- SDS-LDHARS]
The XRD pattern of $\mathrm{LDH}-\mathrm{CO}_{3}$ and SDS- $\mathrm{LDH}$ are represented in Fig. 3. exhibit some common features of LDH, three intense lines at low $2 \theta$ angle corresponding to diffraction by planes (003), (006) and (009) and the peak between 60 and $63^{\circ}(2 \theta)$ is due to (110) plane [47]. After anionic exchange with $\mathrm{CO}_{3}$, the $\mathrm{d}_{003}$ plane peak was shifted towards lower $2 \theta$ value from $11.529^{\circ}$ to11.455 An increase of basal spacing from 7.67 to $7.72 \AA$ was observed, also the average crystallite size was calculated by Scherrer's equation and found to be 5.42 and $5.0 \mathrm{~nm}$ for $\mathrm{LDH}-\mathrm{CO}_{3}$ and SDS- LDH, respectively.

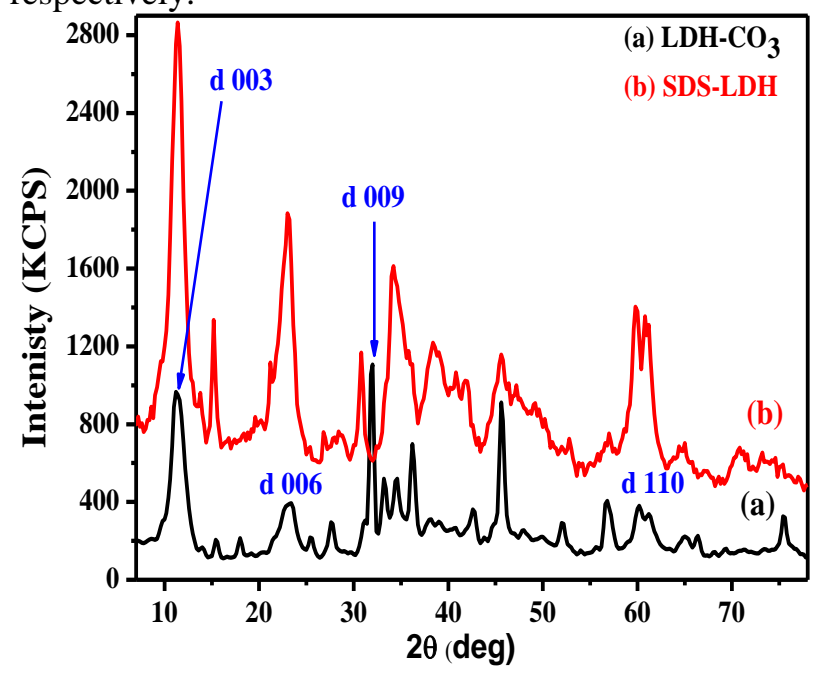

Fig. (3): XRD of $\mathrm{LDH}_{-} \mathrm{CO}_{3}$ and SDS-LDH

The BET surface area of LDH-CO $\mathrm{CO}_{3}$ and SDS-LDH were 72.49 and $62.87 \mathrm{~m}^{2} / \mathrm{g}$. Thermogravimetric analysis, TGA of $\mathrm{LDH}-\mathrm{CO}_{3}$ and SDS-LDH up to $600{ }^{\circ} \mathrm{C}$ are shown in Fig. 4. The weight loss in the range 25-300 ${ }^{\circ} \mathrm{C}$ was nearly equal to 16.6 and $15.7 \%$ may be due to loss of surface adsorbed and interlayer water, while the 
weight loss in the range 300-450 was 14.8 and $20.5 \%$ for $\mathrm{LDH}-\mathrm{CO}_{3}$ and SDS-LDH, respectively due to dehydroxylation from the inorganic layers [48] which indicates that the intercalation of the surfactant does not significantly change the thermal stability of the sorbents.

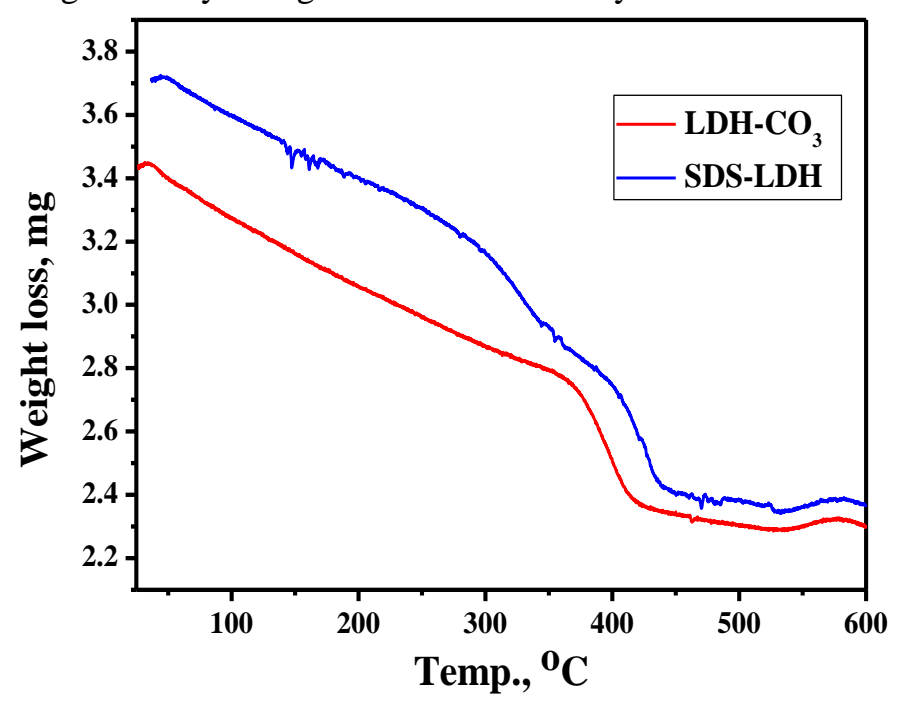

Fig. (4): TGA for $\mathrm{LDH}_{-\mathrm{CO}}$ and SDS-LDH

\subsection{Effect of $\mathrm{pH}$ on the removal of ARS}

The $\mathrm{pH}$ is a critical factor in the sorption process as it affects the surface charges of adsorbents, leading to the electrostatic interactions between the adsorbent and adsorbate[49]. As the $\mathrm{pH}<\mathrm{pHpzc}$, the surface of the adsorbent gains a positive charge and enhances the uptake of ARS due to the electrostatic attraction force and when the $\mathrm{pH}>\mathrm{pHpzc}$, the negatively charged adsorbent could oppose the sorption process. The effect of $\mathrm{pH}$ on the adsorption of ARS onto $\mathrm{LDH}-\mathrm{CO}_{3}$ and SDS-LDH was carried out in the range (2.0-10.0) with a V/m ratio $200 \mathrm{~mL} / \mathrm{g}$, Fig. 5. It is clear that the sorption of Alizarine Red -S remained constant in the range 2.08.0 then decreased with increasing the $\mathrm{pH}$ of the aqueous solution. Even at higher $\mathrm{pH}$ between 8.0 and 10.0, a sorption process was observed which indicates that there is that another interaction, such as complexation, is the primary interaction between $\mathrm{LDH}-\mathrm{CO}_{3}$ or SDS-LDH and ARS. Also at $\mathrm{pH}>8.0$ the ionization of phenolate group that acquires a negative charge on the dye surface was observed [50]. Fig. 6 represents the formula of ARS in extended conformation. All investigations were carried out at $\mathrm{pH} 6.0$ where the predominant species are the neutral species $\mathrm{AH}_{2}$ and the anionic one $\mathrm{AH}^{-}$[51] that enhances the electrostatic interaction with the positively charged surface of the adsorbents [52]. The possible interactions between $\mathrm{LDH}-\mathrm{CO}_{3}$ or SDS-LDH and ARS dye are proposed in Fig.7.

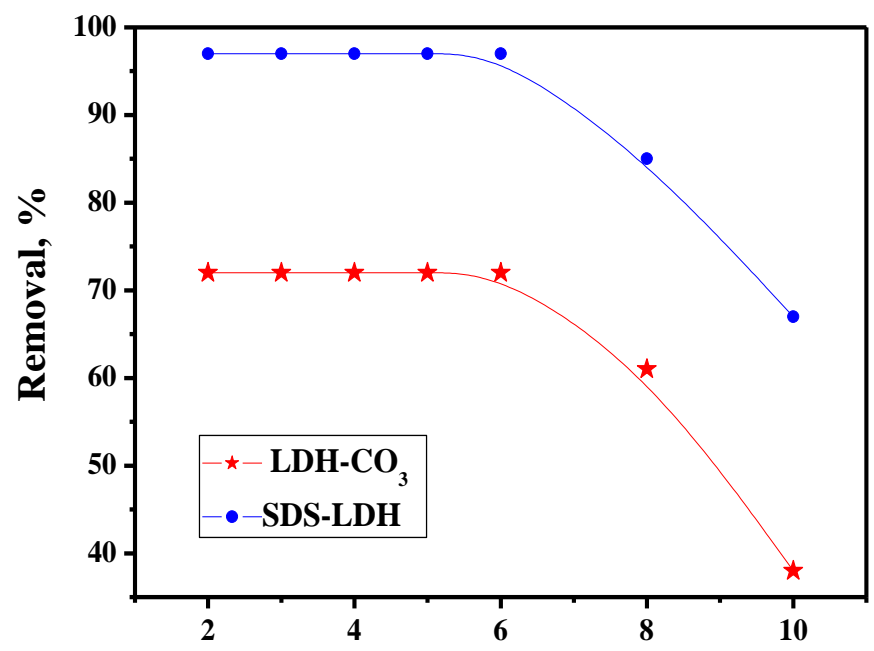

Fig. (5): Effect of initial $\mathrm{pH}$ solution on percentage of ARS removal onto $\mathrm{LDH}^{-\mathrm{CO}_{3}}$ and SDS-LDH: $\mathrm{V} / \mathrm{m}=200$ $\mathrm{mL} / \mathrm{g}, \mathrm{T}: 25 \pm 1^{\circ} \mathrm{C},[\mathrm{ARS}]=100 \mathrm{mg} / \mathrm{L}$
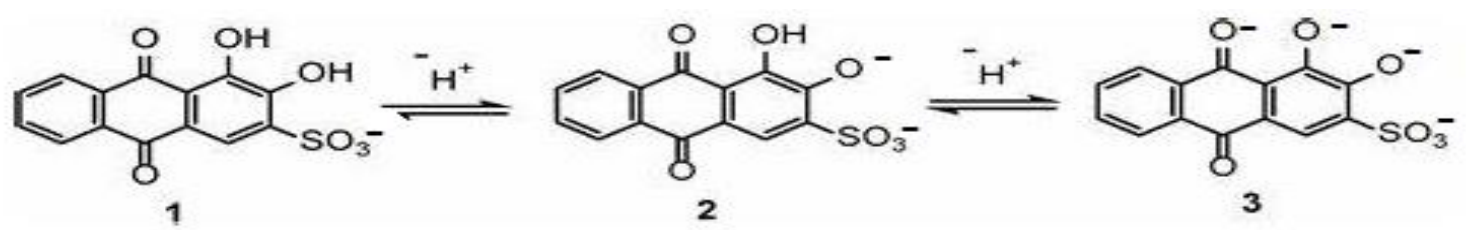

Fig. (6): Formula of ARS in extended conformation

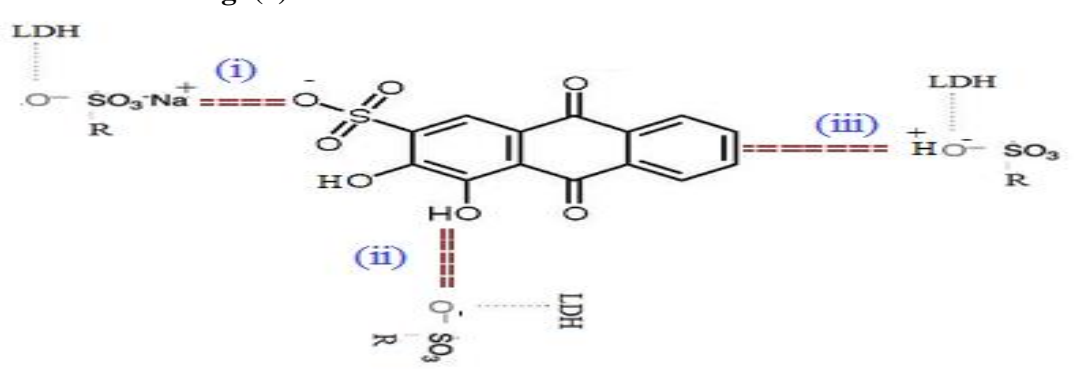

Fig. (7): The SDS-LDH and ARS dye interaction. (i)ionic interaction between SDS-LDH-dye at pH 6; (ii) Hydrogen bond between SDS-LDH-dye ; (iii) Hydrogen bond between SDS-LDH and aromatic residue in the dye 


\subsection{Effect of sorbent dose}

The effect of $\mathrm{LDH}-\mathrm{CO}_{3}$ and SDS-LDH dose on the sorption of Alizarine Red -S ions was investigated in the range $0.01-0.05 \mathrm{~g} / 10.0 \mathrm{~mL}$ solution with $100 \mathrm{mg} / \mathrm{L}$ of Alizarine Red -S at ambient temperature $\left(25^{\circ} \mathrm{C}\right)$ for 30.0 min. As seen from Fig. 8, the percent uptake of ARS increased with increasing the sorbent dose due to the increase in the number of active sites available for adsorption [53]. In this respect $0.05 \mathrm{~g} / 10.0 \mathrm{~mL}$ that corresponds to a $\mathrm{V} / \mathrm{m}$ ratio $200 \mathrm{~mL} / \mathrm{g}$ was used in this investigation.

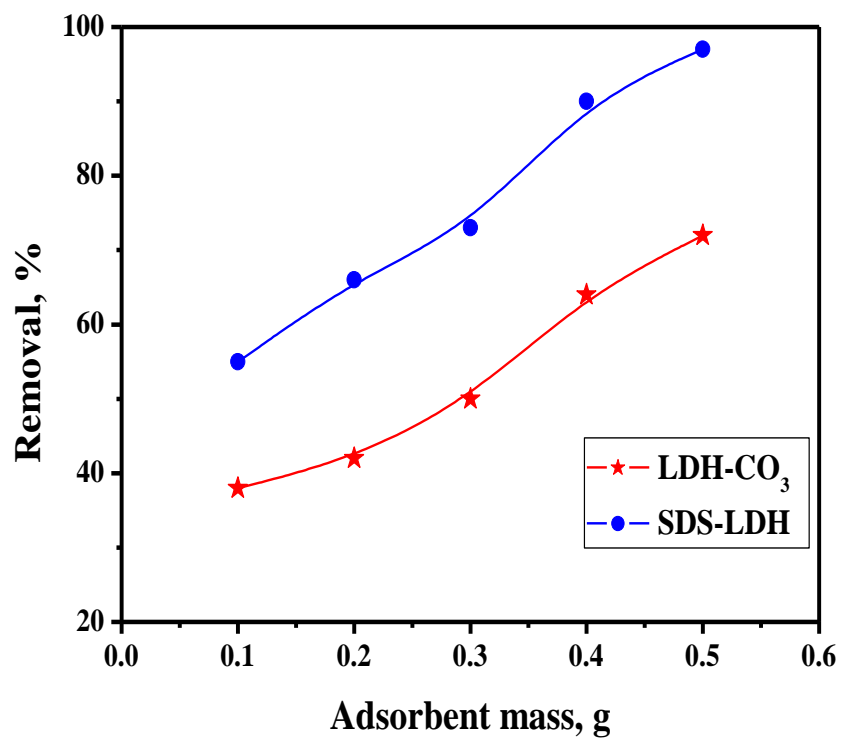

Fig. (8): Effect of adsorbent dose on percentage of ARS removal onto $\mathrm{LDH}-\mathrm{CO}_{3}$ and SDSLDH: pH: 6, T: $25 \pm 1^{\circ} \mathrm{C},[\mathrm{ARS}]=100 \mathrm{mg} / \mathrm{L}$

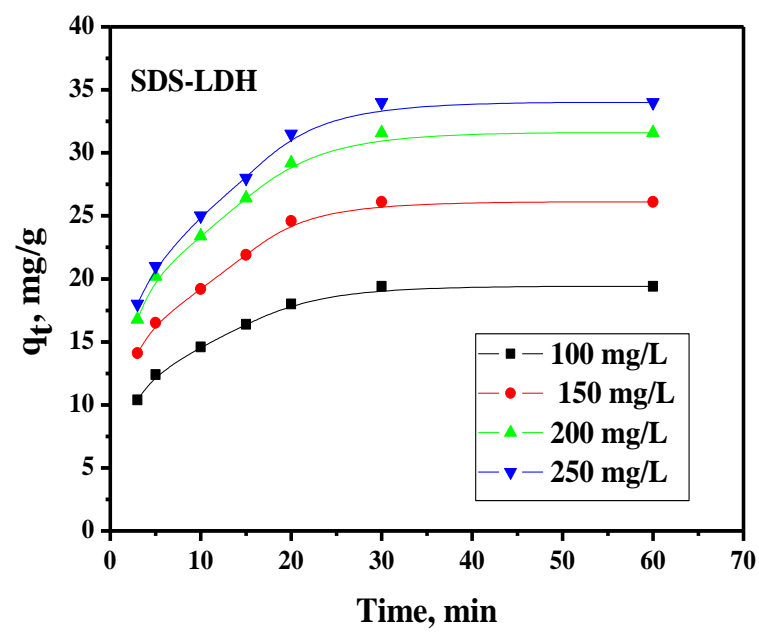

\subsection{Sorption kinetics}

The effect of contact time on the sorption of ARS was investigated in the range between 3.0 and $60.0 \mathrm{~min}$. using ARS concentration of $100 \mathrm{mg} / \mathrm{L}$ onto $\mathrm{LDH}-\mathrm{CO}_{3}$ and SDS-LDH with a V/m ratio $200 \mathrm{~mL} / \mathrm{g}$, Fig. 9. The equilibrium established within $30.0 \mathrm{~min}$. and the intercalation with the surfactant enhanced the uptake of the dye from 72 to $97 \%$.

Four kinetic models were examined to set the order of the sorption. The pseudo- first order kinetic model was estimated according to the equation:

$$
\log \left(q_{e}-q_{t}\right)=\log q_{e}-\left(\frac{k_{1}}{2.303}\right) t
$$

Where $\mathrm{k}_{1}$ is the rate constant of pseudo- first- order $\left(\min ^{-1}\right)$. The values of $k_{1}$ and $\mathrm{q}_{\mathrm{e}}$ can be calculated from the slope and intercept on plotting $\log \left(\mathrm{q}_{\mathrm{e}}-\mathrm{q}_{\mathrm{t}}\right)$ versus $(\mathrm{t})$, Fig. 10 and are reported in Table $(1,2)$. It is clear that the results fit the model in case of $\mathrm{LDH}-\mathrm{CO}_{3}$ system.

The sorption data were investigated by pseudo-second order mechanism according to the equation (4):

$$
\left(\frac{t}{q_{t}}\right)=\left(\frac{1}{k_{2} q_{e}^{2}}\right)+\left(\frac{1}{q_{e}}\right) t
$$

Where $\mathrm{k}_{2}\left(\mathrm{gmg}^{-1} \mathrm{~min}^{-1}\right)$ is the rate constant of the second-order adsorption. The equation constants can be determined by plotting $t / \mathrm{q}_{\mathrm{t}}$ against $\mathrm{t}$, Fig. 11 , and the results are tabulated in Table $(1,2)$. The regression coefficient $\left(\mathrm{R}^{2}\right)$ was around 0.996 . It is clear that the data obtained fit this model as the values of $\mathrm{q}_{\exp }$ are similar to $\mathrm{q}_{\text {cal. }}$ for SDS-LDH system.

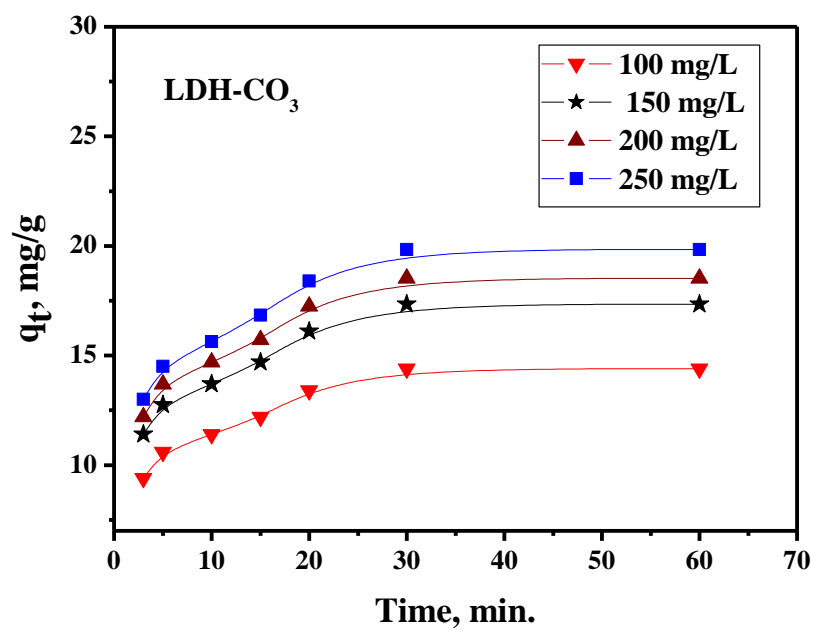

Fig. (9): Effect of contact time on percentage of $\mathrm{ARS}$ removal onto $\mathrm{LDH}-\mathrm{CO}_{3}$ and SDS-LDH: V/m = $200 \mathrm{~mL} / \mathrm{g}, \mathrm{pH}: 6, \mathrm{~T}: 25 \pm 1^{\circ} \mathrm{C},[\mathrm{ARS}]=100 \mathrm{mg} / \mathrm{L}$ 

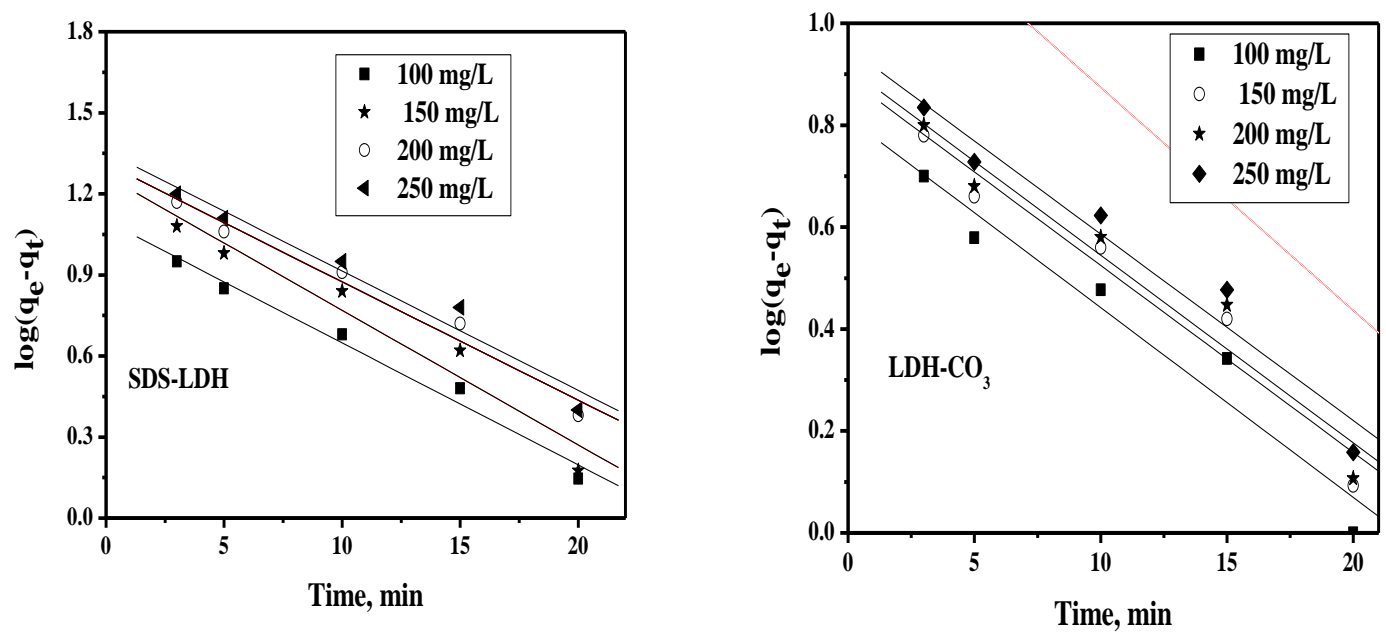

Fig. (10): First order Kinetic model for adsorption of ARS onto $\mathrm{LDH}^{-\mathrm{CO}_{3}}$ and SDS-LDH
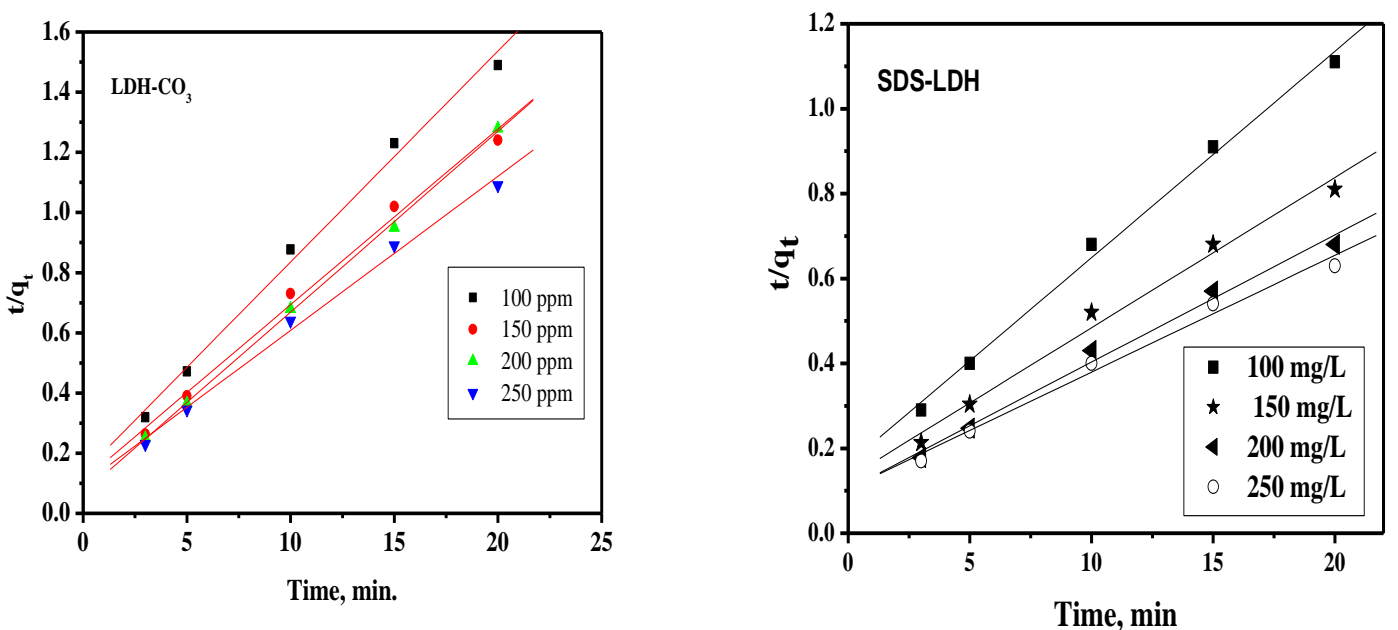

Fig. (11): Second order kinetic model for adsorption of ARS onto $\mathrm{LDH}-\mathrm{CO}_{3}$ and SDS-LDH

Table (1): Calculated parameters of the pseudo first-order, pseudo second-order, intra particle diffusion and Elovich kinetic models of $\mathrm{ARS}$ onto $\mathrm{LDH}-\mathrm{CO}_{3}$

\begin{tabular}{|c|c|c|c|c|c|}
\hline Model & parameters & $\begin{array}{c}100, \\
\mathrm{mg} / \mathrm{L}\end{array}$ & $\begin{array}{c}150 \\
\mathrm{mg} / \mathrm{L}\end{array}$ & $\begin{array}{c}200 \\
\mathrm{mg} / \mathrm{L}\end{array}$ & $\begin{array}{c}250 \\
\mathrm{mg} / \mathrm{L}\end{array}$ \\
\hline$\left[\mathrm{LDH}-\mathrm{CO}_{3}\right]$ & $\mathrm{q}_{\mathrm{e}}, \exp .,(\mathrm{mg} / \mathrm{g})$ & 14.4 & 17.34 & 18.52 & 19.84 \\
\hline \multirow[t]{3}{*}{ First-order kinetic } & $\mathrm{k}_{1}\left(\min ^{-1}\right)$ & 0.104 & 0.115 & 0.099 & 0.101 \\
\hline & $\mathrm{q}_{\mathrm{e}}$, calc. $(\mathrm{mg} / \mathrm{g})$ & 10.23 & 18.62 & 20.51 & 22.70 \\
\hline & $R^{2}$ & 0.980 & 0.947 & 0.974 & 0.960 \\
\hline \multirow{3}{*}{$\begin{array}{l}\text { Second-order } \\
\text { kinetic }\end{array}$} & $\mathrm{K}_{2}\left(\min ^{-1}\right)$ & $1.8 \times 10^{-2}$ & $9.42 \times 10^{-3}$ & $8.66 \times 10^{-3}$ & $6.94 \times 10^{-3}$ \\
\hline & $\mathrm{q}_{\mathrm{e}}$, calc. $(\mathrm{mg} / \mathrm{g})$ & 20.10 & 28.57 & 33.33 & 37.04 \\
\hline & $R^{2}$ & 0.994 & 0.980 & 0.990 & 0.986 \\
\hline \multirow{3}{*}{$\begin{array}{l}\text { Intra- particle } \\
\text { diffusion }\end{array}$} & $\mathrm{k}_{\mathrm{id}}\left(\mathrm{mg} \mathrm{g}^{-1} \min ^{-0.5}\right)$ & 3.919 & 5.328 & 6.384 & 9.73 \\
\hline & $\mathrm{C}$ & 5.975 & 7.857 & 9.571 & 7.019 \\
\hline & $R^{2}$ & 0.994 & 0.984 & 0.990 & 0.988 \\
\hline \multirow[t]{3}{*}{ Elovich } & $a,(\mathrm{mg} / \mathrm{min})$ & 87.88 & 82.43 & 127.10 & 123.84 \\
\hline & $b\left(\mathrm{~g} / \mathrm{mg}^{-1}\right)$ & 0.524 & 0.391 & 0.415 & 0.383 \\
\hline & $R^{2}$ & 0.960 & 0.982 & 0.990 & 0.988 \\
\hline
\end{tabular}


Table (2): Calculated parameters of the pseudo first-order, pseudo second-order, intra particle diffusion and Elovich kinetic models of ARS onto SDS-LDH

\begin{tabular}{cccccc}
\hline Model & parameters & $\begin{array}{c}\mathbf{1 0 0} \\
\mathbf{m g} / \mathbf{L}\end{array}$ & $\begin{array}{c}\mathbf{1 5 0} \\
\mathbf{m g} / \mathbf{L}\end{array}$ & $\begin{array}{c}\mathbf{2 0 0} \\
\mathbf{m g} / \mathbf{L}\end{array}$ & $\begin{array}{c}\mathbf{2 5 0} \\
\mathbf{m g} / \mathbf{L}\end{array}$ \\
\hline [SDS-LDH] & $\mathrm{q}_{\mathrm{e}, \text { exp. }}(\mathrm{mg} / \mathrm{g})$ & 19.40 & 26.10 & 31.60 & 34.0 \\
First-order & $\mathrm{k} 1(\mathrm{~min} .1)$ & 0.104 & 0.115 & 0.099 & 0.101 \\
kinetic & $\mathrm{q}_{\mathrm{e}, \text { calc. }}(\mathrm{mg} / \mathrm{g})$ & 12.59 & 18.62 & 20.42 & 22.70 \\
& $R^{2}$ & 0.980 & 0.947 & 0.974 & 0.960 \\
Second-order & $\mathrm{K}_{2}\left(\mathrm{~min}^{-1}\right)$ & $14.5 \times 10^{-3}$ & $9.64 \times 10^{-3}$ & $8.66 \times 10^{-3}$ & $6.94 \times 10^{-3}$ \\
kinetic & $\mathrm{q}_{\mathrm{e}, \text { calc. }}(\mathrm{mg} / \mathrm{g})$ & 20.57 & 28.25 & 33.33 & 37.04 \\
& $R^{2}$ & 0.988 & 0.976 & 0.976 & 0.976 \\
Intra- particle & $\mathrm{k}_{\mathrm{id}}\left(\mathrm{mg} \mathrm{g}^{-1} \mathrm{~min}^{-0.5}\right)$ & 3.919 & 5.328 & 6.384 & 7.018 \\
diffusion & $\mathrm{C}$ & 5.975 & 7.857 & 9.571 & 9.730 \\
& $R^{2}$ & 0.994 & 0.984 & 0.990 & 0.988 \\
Elovich & $a,\left(\mathrm{mg} / \mathrm{min}^{-1}\right)$ & 88.15 & 85.97 & 126.97 & 123.84 \\
& $\mathrm{~b}\left(\mathrm{~g} / \mathrm{mg}^{-1}\right)$ & 0.524 & 0.443 & 0.415 & 0.383 \\
& $R^{2}$ & 0.960 & 0.962 & 0.962 & 0.966 \\
\hline
\end{tabular}

The intraparticle diffusion model assumes that the adsorption process is diffusion-controlled. The intraparticles diffusion model is expressed by the following equation:

$$
\mathrm{q}_{\mathrm{t}}=\mathrm{k}_{\mathrm{i}} \mathrm{t}^{1 / 2}+\mathrm{C}
$$

Where $\mathrm{k}_{\mathrm{i}}\left(\mathrm{mg} \mathrm{g}^{-1} \mathrm{~min}^{-0.5}\right)$ is the intra-particle diffusion rate constant and $\mathrm{C}$ is the intercept which is proportional to the boundary layer thickness. The plots of $\mathrm{q}(\mathrm{mg} / \mathrm{g})$ against $t^{0.5}$, Fig. 12 gives a linear relationships that do not pass through the origin point This indicates that the intraparticle diffusion is not the dominant mechanism in processes occurring during the sorption of Alizarine Red -S ions and the parameters are listed in Table $(1,2)$.

Elovich model describes the activated chemisorption. In Elovich equation

$$
q_{t}=1 / b \ln (a b)+1 / b \ln t
$$

where $\mathrm{a}$ and $\mathrm{b}$ are constants. The constant $\mathrm{a}$ is considered as the initial sorption rate $(\mathrm{mg} / \mathrm{g} \mathrm{min})$ and (b) is a constant characteristic of the process, Fig.13, the values of $\mathrm{a}$ and $\mathrm{b}$ are listed in Table $(1,2)$. The regression coefficient $\left(\mathrm{R}^{2}\right)$ in that model is less than that of both the pseudo- first and second order models for the two investigated adsorbents which indicates that this model does not fit the data obtained.
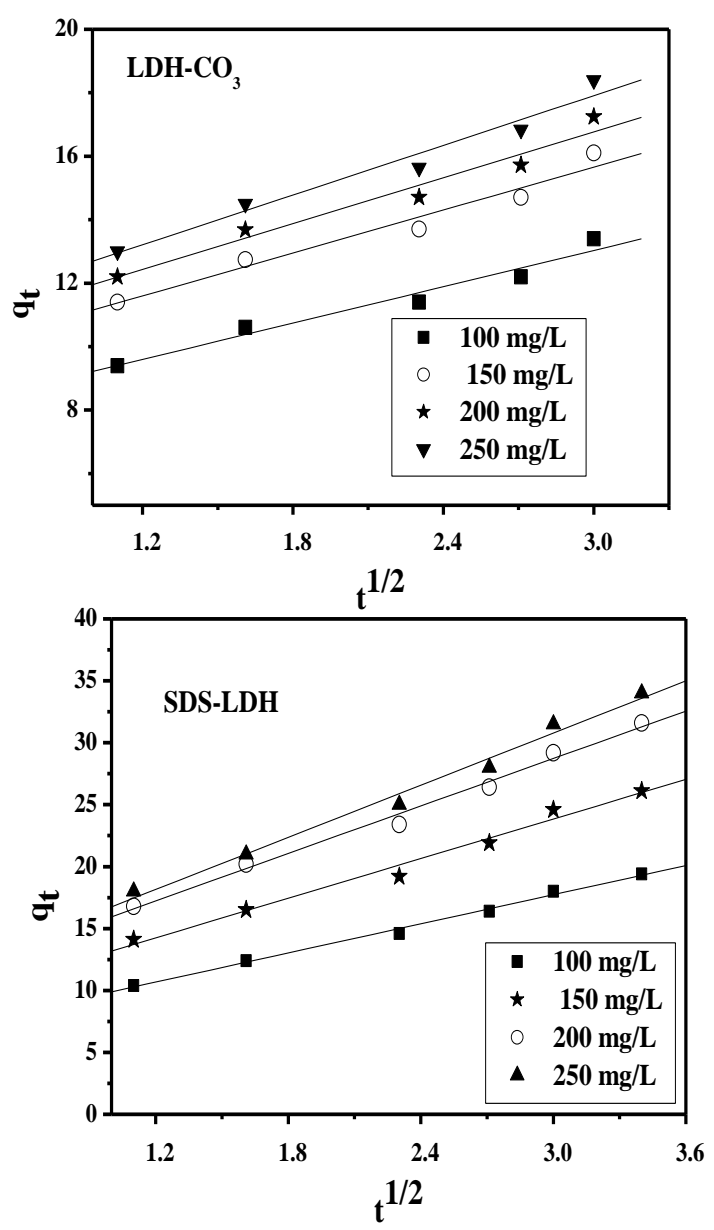

Fig. (12): The intraparticle diffusion kinetic model for the adsorption of ARS onto $\mathrm{LDH}-\mathrm{CO}_{3}$ and SDS-LDH 

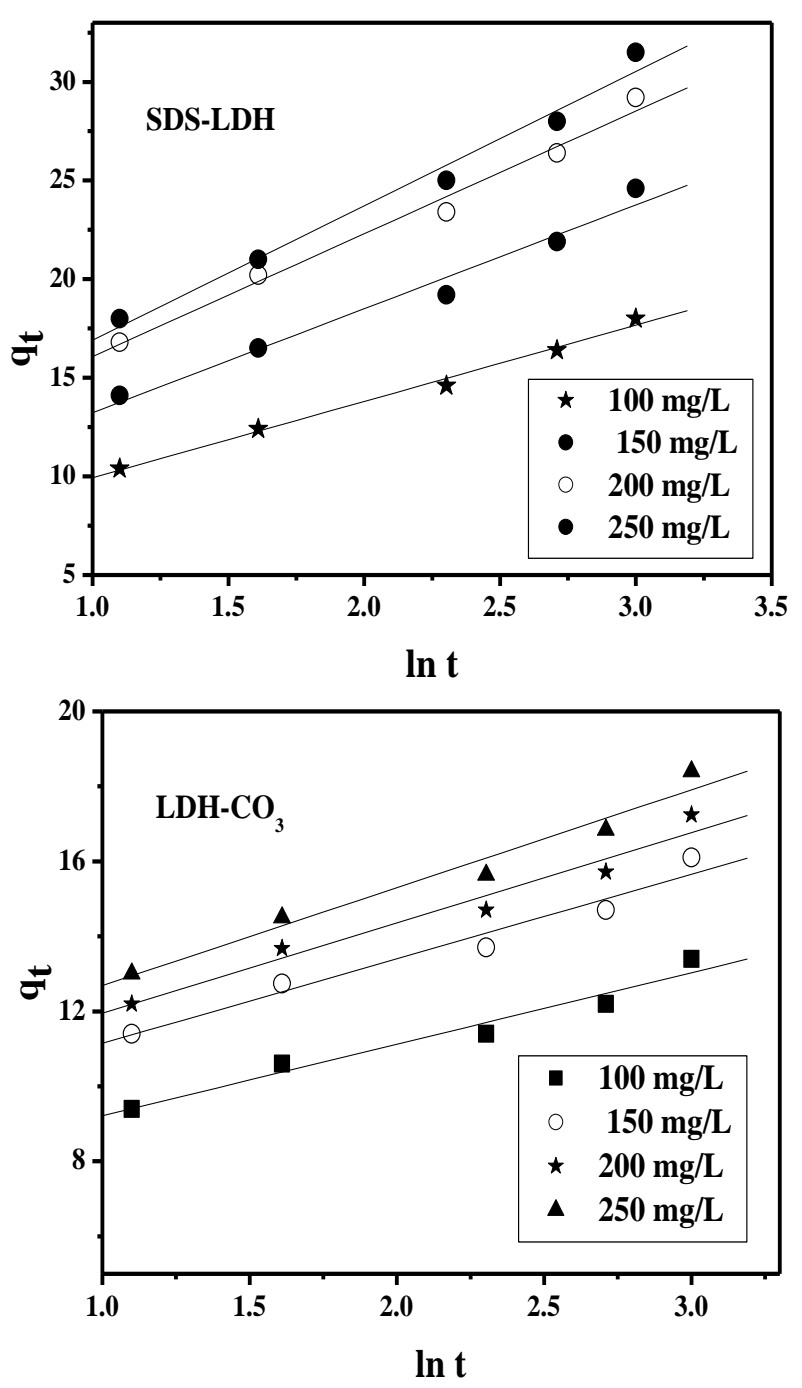

Fig. (13) Elovich kinetic model for the adsorption of ARS onto $\mathrm{LDH}_{-} \mathrm{CO}_{3}$ and SDS-LDH

\subsection{Effect of ARS concentration}

The effect of ARS concentration on its sorption onto LDH-CO3 and SDS-LDH with a V/m ratio $200 \mathrm{~mL} / \mathrm{g}$ was investigated in the range $100-250 \mathrm{mg} / \mathrm{L}$ at ambient temperature, Fig. 14. indicates that the amount of ARS sorbed onto the sorbents increased with increasing the initial dye concentration due to increasing the driving force for mass transfer with the increase in ARS concentration [54].

Langmuir and Freundlich models are commonly used to evaluate the equilibrium adsorption. In Langmuir isotherm model, the linear form is represented by the following equation:

$$
\frac{C_{e}}{q_{e}}=\frac{1}{q_{\max } b}+\frac{1}{q_{\max }} C_{e}
$$

Where, $\mathrm{Q}_{\max }$ is the saturated monolayer adsorption $(\mathrm{mg} / \mathrm{g}), \mathrm{b}$ is the Langmuir constant sites and is a measure of the adsorption energy $\mathrm{mL} / \mathrm{mg}$. The results are illustrated in Fig. 15 and Table (3). $\mathrm{R}_{\mathrm{L}}$, Langmuir isotherm is a dimensionless constant that is called equilibrium parameter and can be calculated from the following equation

$$
R_{L}=\frac{1}{1+b C_{o}}
$$

The value of $\mathrm{R}_{\mathrm{L}}$ was found to be $0<\mathrm{R}_{\mathrm{L}}<1$ that means the sorption process is favorable, Table (3).

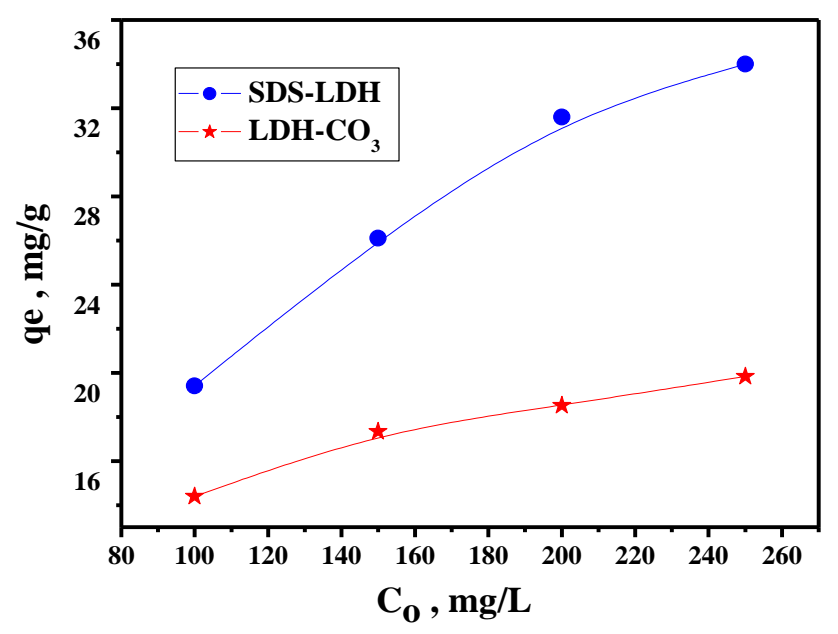

Fig. (14): Effect of initial ARS concentration on its removal onto $\mathrm{LDH}-\mathrm{CO}_{3}$ and SDS-LDH: $\mathrm{V} / \mathrm{m}=200 \mathrm{~mL} / \mathrm{g}$, pH: $6, \mathrm{~T}: 25 \pm 1^{\circ} \mathrm{C}$

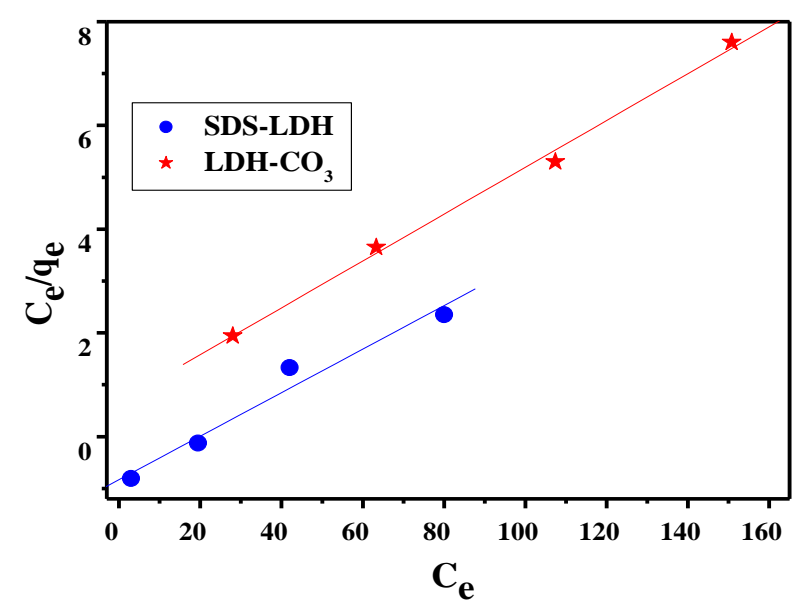

Fig. (15): Langmuir Plots for the adsorption of Alizarine Red -S onto $\mathrm{LDH}-\mathrm{CO}_{3}$ and SDS- $\mathrm{LDH}: \mathrm{V} / \mathrm{m}=200 \mathrm{~mL} / \mathrm{g}$, $\mathrm{pH}$ : 6, $\mathrm{T}: 25 \pm 1^{\circ} \mathrm{C}$

The Freundlich model is commonly represented as:

$$
\log q_{e}=\log K_{f}+(1 / n) \log C_{e}
$$

Where, $\mathrm{K}_{\mathrm{f}}$ and $\mathrm{n}$ are the Freundlich constants characteristics of the system, indicating the adsorption capacity and the adsorption intensity, respectively. The plot of $\log q_{e}$ against $\log C_{e}$ is shown in Fig. 16; the value of $n$ and $K_{f}$ is tabulated in Table (3). 
Table (3): Langmuir and Freundlich constants for Alizarine Red-S adsorption onto $\mathrm{LDH}-\mathrm{CO}_{3}$ and SDS-LDH

\begin{tabular}{ccc}
\hline Model & Parameters & Value \\
\hline \multirow{3}{*}{ Langmiur } & LDH-CO 3 adsorbent & \\
& Qmax $(\mathrm{mg} / \mathrm{g})$ & 22.22 \\
& $\mathrm{~b}(\mathrm{~L} / \mathrm{g})$ & 0.066 \\
Freundlich & $\mathrm{R}_{\mathrm{L}}$ & 0.132 \\
& $\mathrm{R}^{2}$ & 0.996 \\
& $\mathrm{1} / \mathrm{n}(\mathrm{mg} / \mathrm{g})(\mathrm{L} / \mathrm{mg})^{1 / \mathrm{n}}$ & 0.098 \\
& $\mathrm{R}$ & 0.996 \\
& $\mathrm{SDS}-\mathrm{LSH}$ adsorbent & \\
& $\mathrm{Qmax}(\mathrm{mg} / \mathrm{g})$ & 23.87 \\
Langmiur & $\mathrm{b}(\mathrm{L} / \mathrm{g})$ & 0.05 \\
& $\mathrm{R}_{\mathrm{L}}$ & 0.176 \\
& $\mathrm{R}^{2}$ & 0.964 \\
& $1 / \mathrm{n}$ & 0.173 \\
Freundlich & $\mathrm{Kf}(\mathrm{mg} / \mathrm{g})(\mathrm{L} / \mathrm{mg})^{1 / \mathrm{n}}$ & 16.069 \\
& $\mathrm{R}^{2}$ & 0.992 \\
\hline
\end{tabular}

In case of $\mathrm{LDH}-\mathrm{CO}_{3}$ system, both Langmuir and Freundlich models are applicable as the regression coefficient $\left(\mathrm{R}^{2}\right.$ around 0.996$)$ that implies that the sorption fit the Langmiur model at low concentration and at higher concentration of the adsorbate the system obeys Freundlich model. In SDS-LDH system, Freundlich model is applicable as the regression coefficient $\mathrm{R}^{2}=0.992$ is much higher than that obtained by Langmuir model $R^{2}=0.964$ which indicates that the dye adsorption process is affected by its own intermolecular interaction between the adsorbed dye molecules. The value of $1 / \mathrm{n}<$ 1 (0.17) shows favorable multilayer sorption of ARS from aqueous medium onto SDS-LDH.

A comparison of the adsorption capacity of LDH$\mathrm{CO}_{3}$ and SDS-LDH with other adsorbents is reported in Table 4. The results implied that $\mathrm{LDH}-\mathrm{CO}_{3}$ and SDSLDH can be used efficiently for the removal of ARS from aqueous medium.

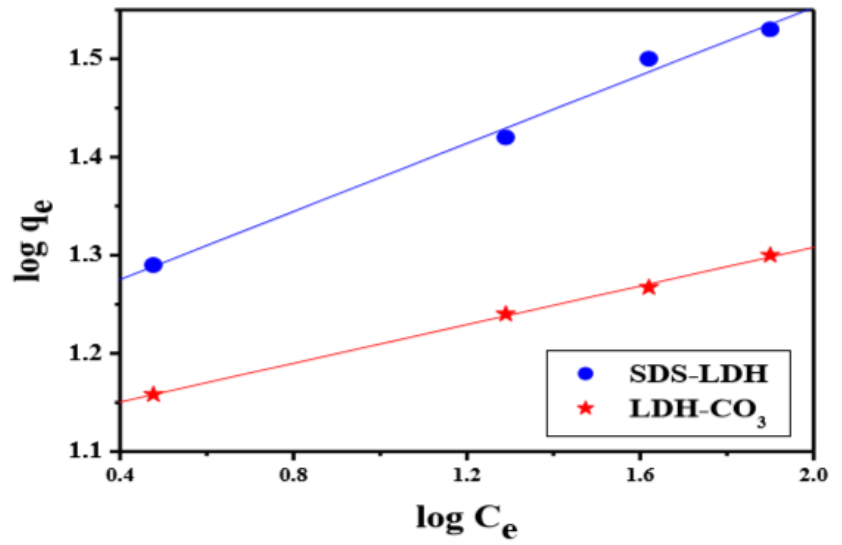

Fig. (16): Freundlich Plots for the adsorption of Alizarine Red $-\mathrm{S}$ onto $\mathrm{LDH}-\mathrm{CO}_{3}$ and SDS- $\mathrm{LDH}: \mathrm{V} / \mathrm{m}=200 \mathrm{~mL} / \mathrm{g}$, pH: 6, T: $25 \pm 1^{\circ} \mathrm{C}$

Table (4): Comparison of sorption capacities for Alizarine Red -S using various adsorbent materials

\begin{tabular}{lrc}
\hline Sorbent & $\begin{array}{c}\mathbf{Q}_{\mathbf{m a x}}, \\
\mathbf{m g} / \mathbf{g}\end{array}$ & Ref. \\
\hline $\mathrm{Fe}_{3} \mathrm{O}_{4} @$ AMP-Tb & 357.14 & {$[52]$} \\
CS-IMBTESPEDA-SBA-15 & 50.25 & {$[55]$} \\
polypyrrole-coated magnetic nanoparticles & 116.30 & {$[56]$} \\
Magnetic chitosan & 40.10 & {$[57]$} \\
Cynodondactylon & 16.30 & {$[58]$} \\
PEI@MCNTs & 196.08 & {$[59]$} \\
Activated Carbon & 385.0 & {$[60]$} \\
MCNTs & 161.29 & {$[61]$} \\
Catechol-Amine Resin-hydrocelluose composite & 284.09 & {$[62]$} \\
LDH-CO & 22.22 & This study \\
SDS-LDH & 23.87 & This study \\
\hline
\end{tabular}

\subsection{Regeneration experiments}

Desorption studies on the loaded $\mathrm{LDH}-\mathrm{CO}_{3}$ and SDSLDH were carried out using $0.1 \mathrm{M}$ sodium hydroxide solution at $25{ }^{\circ} \mathrm{C}$ for $15 \mathrm{~min}$. The desorption percentage was found to be 85 and $90 \%$ for the loaded $\mathrm{LDH}-\mathrm{CO}_{3}$ and SDS-LDH, respectively. In that alkaline condition, the predominant species of ARS is species 3, Fig. 6 that repel with the negative charge of the adsorbent.

\section{CONCLUSION}

$\mathrm{LDH}-\mathrm{CO}_{3}$ and intercalated SDS-LDH were investigated for the sorption of the carcinogenic, anionic dye, Alizarine Red-S to investigate the efficiency of both adsorbents for the potential removal of such dye. Intercalation with sodium dodecyl sulphate slightly improved the sorption processes. Sorption experimental data were analysed in term of kinetic models. The experimental data fitted well with the pseudo -first-order model for $\mathrm{LDH}-\mathrm{CO}_{3}$ and pseudo -second-order model for SDS-LDH. The adsorbents could be regenerated 
through the desorption of ARS using $0.1 \mathrm{M} \mathrm{NaOH}$ solution and could be reused.

\section{Acknowledgment}

I wish to express my sincere gratitude to Prof. Dr. J. A. Daoud and Prof. Dr. H. F. Aly, Atomic Energy Authority- Egypt, for their fruitful discussions and text reviewing.

\section{REFERENCES}

[1] Calabrese, E., Kostecki, P., Dragun J. (2006) Contaminated Soils, Sediments and Water, Successes and Challenges, Vol. 10 (Springer, NY) 227-237.

[2] Rizk, S., Hamed, M. (2015) Batch sorption of iron complex dye, naphthol green $\mathrm{B}$, from wastewater on charcoal, kaolinite, and tafla, Desalin Water Treat, 56, 1536-1546.

[3] Hamed M. (2014) Sorbent extraction behavior of a nonionic surfactant, Triton X-100, onto commercial charcoal from low level radioactive waste, J Radioanal. Nucl. Chem. 302, 303-313.

[4] Gharbani, P., Tabatabaii, S., Mehrizad, A. (2008) Removal of Congo Red from textile wastewater by ozonation, Int. J. Environ. Sci. Tech. 5(495), 495500 .

[5] Adyel, T., Rahman, S., Zaman, M., Hossain, M., Sayem, H., Mala, K., Abdul Gafur, Md., Islam, S. (2013) Reuse Feasibility of Electrocoagulated Metal Hydroxide Sludge of Textile Industry in the Manufacturing of Building Blocks, J.Waste. Manag. Article ID. 68698 (1) 1-9.

[6] Adyel, T., Rahman, S., Islam, S., Sayem, H., Khan, M., Zaman, M. (2012) Geo-engineering potentiality of electrocoagulated metal hydroxide sludge (EMHS) from textile industry and EMHS amended soil for using as building material, Inter J Curr Res, 4(2), 21-25.

[7] Rafaie, H., Nor, R., Azmina, M., Ramli, N., Mohamed, R. (2017) Decoration of $\mathrm{ZnO}$ microstructures with Ag nanoparticles enhanced the catalytic photodegradation of methylene blue dye, J Environ Chem Eng. 5 (4), 3963- 3972.

[8] Sheng, S., Liu, B., Hou, X., Wu, B., Yao, F., Ding, X., Huang, L. (2018) Aerobic Biodegradation Characteristic of Different WaterSoluble Azo Dyes, Int. J. Environ. Res. Public Health. 15(1) (2018) 35-40
[9] A. Konsowa, H. Abd El-Rahman, F. (2011) Removal of azo dye acid orange using aerobic membrane bioreactor. Alex. Eng. J. 50(1), 117125.

[10] Waleed, M., Alabdraba, M., Aldoury, M. Bayati, M. (2014) Performance of Sequential Anaerobic/Aerobic Biological Treatment of Synthetic Wastewater Containing Two Types of Azo Dye. Conference: ICOEST'2, Turkey.

[11] Singh, S., Sidhu, G., Singh, H. (2017) Removal of methylene blue dye using activated carbon prepared from biowaste precursor, Indian Chem. Eng. 61(1), 28-39.

[12] Greluk, M., Hubicki, Z. (2011) Efficient removal of acid orange 7 dye from water using the strongly basic anion exchange resin Amberlite IRA-958, Desalination. 278 (1-3), 219-226

[13] Shao, J., Cheng, Y., Yang, C., Zeng, G., Liu, W., Jiao, P., He, H. (2016) Efficient removal of naphthalene-2-ol from wastewater by solvent extraction, J. Environ. Sci. 47(9),120-129

[14] Chen, G., Lei, L., Yue, P. (1999) Wet oxidation of high-concentration reactive dyes, Ind. Eng. Chem. Res. 38, 1837-1843.

[15] Tan, B., Teng, T., Omar, A. (2000) Removal of dyes and industrial dye wastes by magnesium chloride, Water Res. 34(2) 597-600.

[16] Park, Y., Ayoko, G., Frost, R. (2011) Application of organoclays for the adsorption of recalcitrant organic molecules from aqueous media, J. Colloid Interface Sci. 354, 292-305J.

[17] Baptisttella, A., Araújo, A., Barreto, M., Motta, M. (2018)The use of metal hydroxide sludge (in natura and calcined) for the adsorption of brilliant blue dye in aqueous solution. Environ Technol 40(2),1-35.

[18] Attallah, M., Ahmed, I.M., Hamed, M. (2013) Treatment of industrial wastewater containing Congo Red and Naphthol Green B using low-cost adsorbent, ESPR. 20, 1106-1116.

[19] Xue, S., Zhu, F., Kong, X., Wu, C., Huang, L., Huang, N., Hartley, W. (2016) A review of the characterization and revegetation of bauxite residues (Red mud), Environ. Sci. Pollut. R. 23, 1120-1132.

[20] Yalçın, N., Sevinç, V. (2000) Utilization of bauxite waste in ceramic glazes, Ceramics Inter. 26 (5), 485-493 
[21] Tor, A., Cengeloglu, Y. (2006) Removal of congo red from aqueous solution by adsorption onto acid activated red mud, J. Hazard. Mater. B.138, 409415.

[22] Fu, F., Dionysioub, D., Liu, H. (2014) The use of zero-valent iron for groundwater remediation and wastewater treatment: A review, J. Hazard. Mater. 267, 194-205.

[23] Narbaitz, R., Karimi-Jashni, A. (2009) Electrochemical regeneration of granular activated carbons loaded with phenol and natural organic matter. Environ. Technol., 30, 27-36.

[24] Adeyemo, A., Adeoye, I., Bello, O. (2017) Adsorption of dyes using different types of clay: a review. Appl. Water Sci.7, 543-568.

[25] Argun, Y., Tunç, A., Çalışır, U., Irak, H. (2017) Bisorption method and biosorptions for dye removal from industrial wastewater: A Review, Inter. J. Adv. Res.5(8),707-714.

[26] Pushpa, T., Jegan, J., Saravanan, P., Ravindiran, G. (2019) Biodecolorization of Basic Blue 41 using EM based Composts: Isotherm and Kinetics. Chem. Select 4(34), 10006 -10012.

[27] Karim, Md., Dhar, K., Hossain, Md. (2016) Cometabolic decolorization of a textile reactive dye by Aspergillus fumigatus. Inter. J. Environ. Sci. Technol. 14,177-186.

[28] Trifiro, F., Vaccari, A. (1996) Oxford, UK: Pergamon Press Hydrotalcite-like anionic clays (Layered double hydroxides). In: Davies, J. E. D., Atwood, J. L., MacNicol, D. Vogtle, F. (Eds), Comprehensive Supramolecular Chemistry, Oxford, UK: Pergamon Press, p.251-291.

[29] Ahmed, I.M., Gasser, M. (2012) Adsorption Study of Anionic Reactive Dye from Aqueous Solution to $\mathrm{Mg}-\mathrm{Fe}-\mathrm{CO}_{3}$ Layered Double Hydroxide (LDH). Appl. Surf. Chem. 259, 650-656.

[30] Kameda, T., Takeuchi, H., Yoshioka, T. (2008) Uptake of heavy Alizarine Red-S from aqueous solution using Mg-Al layered double hydroxides intercalated with citrate, malate, and tartrate, Separ. Purif. Technol. 62(2), 330-336.

[31] Kameda, T., Takeuchi, H.,Yoshioka, T. (2015) Uptake of $\mathrm{Nd}^{3+}$ and $\mathrm{Sr}^{2+}$ by $\mathrm{Li}-\mathrm{Al}$ layered double hydroxide intercalated with triethylenetetraminehexaacetic acid: kinetic and equilibrium studies, RSC Adv. 5, 79447-79455.
[32] Kameda, T., Takeuchi, H., Yoshioka, T. (2016) Uptake of $\mathrm{Nd}^{3+}$ and $\mathrm{Sr}^{2+}$ by $\mathrm{LiAl}$ layered double hydroxides intercalated with ethylenediaminetetraacetate, Mater. Chem. Phys. $177,8-11$

[33] Koilraj, P., Kamura, Y., Sasaki, K. (2017) Carbondot-decorated layered double hydroxide nanocomposites as a multifunctional environmental material for Coimmobilization of $\mathrm{SeO}_{4}{ }^{2-}$ and $\mathrm{Sr}^{2+}$ from aqueous solutions, ACS Sustain. Chem. Eng. 5(10), 9053-9064.

[34] Yao, W., Yu, S., Wang, J., Zou, Y., Lu, S., Ai, Y., Alharbi, N., Alsaedi, A., Hayat, T.,Wang, X. (2017) Enhanced removal of methyl orange on calcined glycerol-modified nanocrystallined $\mathrm{Mg} / \mathrm{Al}$ layered double hydroxides, Chem. Eng. J., 307, 476-486.

[35] Aguiar, J., Bezerra, B., Braga, B., Lima, P., Nogueira, R., Lucena, S., Da Silva, I. (2013)Adsorption of Anionic and Cationic Dyes from Aqueous Solution on Non-Calcined $\mathrm{Mg}-\mathrm{Al}$ Layered Double Hydroxide: Experimental and Theoretical Study, Sep. Sci. Technol. 248, 23072316.

[36] Pahalagedara, M., Samaraweera, M., Dharmarathna, S., Kuo, C., Pahalagedara, L., Gascón, J Suib, S. (2014) Removal of Azo Dyes: Intercalation into Sonochemically Synthesized NiAl Layered Double Hydroxide, J. Phys. Chem. C 118(31), 17801-17809.

[37] Blaisi, N., Zubair, M., Ihsanullah, M., Ali, S., Kazeem, T., Manzar, M., Al-Kutti, W., Al Harthi, M. (2018) Date palm ash-MgAl-layered double hydroxide composite: sustainable adsorbent for effective removal of methyl orange and eriochrome black-T from aqueous phase, Environ Sci Pollut Res Int. Environ. Sci. Pollut. Res. Int., 25(34), 34319-34331.

[38] Tan, X., Liu, Y., Gu, Y., Liu, S., Zeng, G., Cai, X., Hu, X., Wang, H., Liu, S., Jiang, L. (2016) Biochar pyrolyzed from MgAl-layered double hydroxides pre-coated ramie biomass ( Boehmeria nivea ( L .) Gaud .): Characterization and application for crystal violet removal, J. Environ. Manage. 15(184), 1-9.

[39] Zhu, L. Chen, T. Yan, J. Xu, Y. Wang, M. Chen, H. Jiang, F. (2018) Fabrication of $\mathrm{Fe}_{3} \mathrm{O}_{4} / \mathrm{MgAl}$-layered double hydroxide magnetic composites for the effective removal of Orange II from wastewater, Water Sci Technol. 78(5-6), 1179 -1188. 
[40] Dizge, N., Aydiner, C., Demirbas, E., Kobya, M., Kara,S. (2005)Adsorption of reactive dyes from aqueous solutions by fly ash: kinetic and equilibrium studies, J Hazard. Mater.150(3), 737-46

[41] Safavi, A., Bagheri, M. (2005) A novel optical sensor for uranium determination, Analytica Chimica Acta. 530(1), 155-160 .

[42] Hernández, J., Méndez, B., Cordero, M., Gutierrez, L., Dávila, L. (1985) Spectrophotometric determination of zirconium with alizarin red $S$ in the presence of polyvinylpyrrolidone. Analytica Chimica Acta. 175, 345-348.

[43] Leng, S.F., Jing , Y., Wei , Q., Wang, Y., Lv, Y., Wang, X., Zhu, X. (2016) Spectrophotometric method for determination of trace aluminum with application of Alizarin Red. Bulgarian Chemical Communications, 48(1),159-164.

[44] Mahmoud, M., Someda, H. (2012) Mg-Al layered double hydroxide intercalated with sodium lauryl sulfate as a sorbent for ${ }^{152+154} \mathrm{Eu}$ from aqueous solutions. J. Radioanal. Nucl. Chem . 292,13911400 .

[45] Moriguchi, T.,Yano, K., Nakagawa, S., Kaji, F. (2003) Elucidation of adsorption mechanism of bone-staining agent alizarin red Son hydroxyapatite by FT-IR microspectroscopy J. Colloid Interface Sci. 260,19-25.

[46] Millange, F., Walton, R.I., D. O’Hare, D. (2000) Time-resolved in situ X-ray diffraction study of the liquid-phase reconstruction of $\mathrm{Mg}^{2+}-\mathrm{Al}^{3+}$ - carbonate hydrotalcite-like compounds. J. Mater. Chem. 10, 1713-1720.

[47] Ahmed, I. M. and Gasser, M.S. (2012) Adsorption Study of Anionic Reactive Dye from Aqueous Solution toMg-Fe- $\mathrm{CO}_{3}$ Layered Double Hydroxide (LDH), Appl. Surf. Chem., 259, 650-656.

[48] Mandal, S., Tripathy, S., Padhi, T., Sahu, M., Patel, R. (2013) Removal efficiency of fluoride by novel $\mathrm{Mg}-\mathrm{Cr}-\mathrm{Cl}$ layered double hydroxide by batch process from water, J. Environ. Sci. 25(5), 9931000 .

[49] Hamed, M., Ahmed, I.M., Metwally, S. (2014) Adsorptive removal of methylene blue as organic pollutant by marble dust as eco-friendly sorbent, J Ind Eng Chem 20(4), 2370-2377.

[50] Ahmed, I.M., Aglan, R., Hamed., M. (2017) Removal of Arsenazo-III and Thorin from radioactive waste solutions by adsorption onto lowcost adsorbent, J. Radioanal. Nucl. Chem. 314, 2253-2262.

[51] Turcanu, A., Bechtold,T. (2011) pH Dependent redox behaviour of Alizarin Red S (1,2-dihydroxy9,10-anthraquinone-3-sulfonate) - Cyclic voltammetry in presence of dispersed vat dye, Dyes and Pigments. 91(3), 324-331.

[52] Huanga, W., Deng, J., Zhou, T., Lu, D., Shi, G., $\mathrm{Xu}$, J. (2018) Rational design of magnetic infinite coordination polymer core-shell nanoparticles as recyclable adsorbents for selective removal of anionic dyes from colored wastewater, Appl. Surf. Sci. 462, 453-465.

[53] Ahmed, I.M., Attia, L., Attallah. M. (2020) Modification of perlite to prepare low cost zeolite as adsorbent material for removal of ${ }^{144} \mathrm{Ce}$ and ${ }^{152+154} \mathrm{Eu}$ from aqueous solution, Radiochim. Acta. https://doi.org/10.1515/ract-2019-3221.

[54] Metwally, S., Ayoub, R., Aly, H.F. (2014) Utilization of low-cost sorbent for removal and separation of ${ }^{137} \mathrm{Cs},{ }^{60} \mathrm{Co}$ and ${ }^{152+154} \mathrm{Eu}$ radionuclides from aqueous solution, J. Radioanal. Nucl. Chem. 302, 441-449.

[55] Pourebrahim, F., Ghaedi, M., Dashtian, K., Heidari, F., Kheirandish, S. (2017) Simultaneous removing of $\mathrm{Pb}^{2+}$ ions and alizarin red $\mathrm{S}$ dye after their complexation by ultrasonic waves coupled adsorption process: Spectrophotometry detection and optimization study, Ultrason. Sonochem. 35, 51-60.

[56] Gholivand, M., Yamini, Y., Dayeni, M., Seidi, S., Tahmasebi, E. (2015) Adsorptive removal of alizarin red-S and alizarin yellow GG from aqueous solutions using polypyrrole-coated magnetic nanoparticles. J. Environ. Chem. Eng. 3(1), 529-540.

[57] Fan, L., Zhang, Y., Li, X., Luo, C., Lu, F., Qiu, H. (2012) Removal of alizarin red from water environment using magnetic chitosan with alizarin red as imprinted molecules. Colloids Surf B: Biointerfaces.91, 250-257.

[58] Samusolomon, J., Devaprasath, P.M. (2011) Removal of Alizarin Red S (Dye) from Aqueous Media by using Cynodon dactylon as an Adsorbent, J. Chem. Pharm, Res, 3, 478-490.

[59] Zhang, Z., Chen, H., Wu, W., Pang, W., Yan, G. (2019) efficient removal of Alizarin Red $S$ from aqueous solution by polyethyleneimine functionalized magnetic carbon nanotubes. Biores. Technol. 293, 122100 . 
[60] Benhmidene, A., Hidouri, K., Amor, H., Chaouachi, B. (2017) Kinetic Models of Adsoption on Active Carbon, DSAC36-24 Global J. Res Eng.: C Chem. Eng. 17(3), 1-10.

[61] Ghaedi, M., Hassanzadeh, A., Kokhdan, S. (2011) Multiwalled Carbon Nanotubes as Adsorbents for the Kinetic and Equilibrium Study of the Removal of Alizarin Red S and Morin, J. Chem. Eng. Data. 56(5), 2511-2520.
[62] Liu, Q., Wu, Z., Wu, Y., Gao, T., Yao, J. (2107) Efficient Removal of Methyl Orange and Alizarin Red $\mathrm{S}$ from $\mathrm{pH}$-Unregulated Aqueous Solution by the Catechol-Amine Resin Composite Using Hydrocellulose as Precursor, CS Sustainable Chem. Eng. 5(2), 1871-1880. 